\title{
Application of Probiotic Preparation Based on Bacteria of the Genus Bacillus in Experimental Intoxication with Cadmium
}

\author{
Aleksey Sizentsov 1, *(D), Yaroslav Sizentsov ${ }^{1}$ (D), Elena Barysheva ${ }^{1}$ (D), Elena Bibartseva ${ }^{\text {(D) }}$, Ludmila \\ Bykova $^{1}$ (D), Yuliya Plotnikova 1 (D) \\ 1 Orenburg state university, st. Pobedy 13, Orenburg, 460018, Russia \\ * Correspondence kwan111@yandex.ru
}

Scopus Author ID 57216628255

Received: 20.05.2020; Revised: 14.06.2020; Accepted: 15.06.2020; Published: 18.06.2020

\begin{abstract}
Experimental studies show that the introduction of various heavy metals in the form of their soluble salts in laboratory animals can lead to toxic damage to the body. Taking into account the world community's concern with acute and chronic intoxication with heavy metals, methods of detoxification of heavy metal excess, as well as their active removal from the body, are actively being developed today. A relatively new and safe method of detoxification is the use of probiotic strains that have the ability to bind heavy metals, for example, encrusting them in their cell wall, and further, withdrawing through the gastrointestinal tract.

This work conducts a comprehensive assessment of the effectiveness of probiotic preparations as a means of correction of the elemental status in the intoxication with cadmium based on the study of biochemical parameters of serum, histological examination of the liver.

The best effect and preservation of the structure of the main cell population of the liver - hepatocytes was observed in samples with Vetom 2 against the background of intoxication with cadmium during all the periods of observation. There were no microcirculation violations in the liver lobule areas. Studies of the ability of bacteria of the genus Bacillus that are part of the studied probiotics to accumulate heavy metals by means of determining their concentration in tissues of laboratory animals revealed that the preparations contribute to a pronounced decrease in the concentration of cadmium ions in the tissues. At the same time, the bone and muscle tissues have the greatest accumulating ability in relation to cadmium ions. The most effective preparations in cadmium intoxication are Sporobacterin and Vetom 2.
\end{abstract}

Keywords: cadmium; probiotic strains; blood biochemistry; biocorrection of the element status.

(C) 2020 by the authors. This article is an open-access article distributed under the terms and conditions of the Creative Commons Attribution (CC BY) license (https://creativecommons.org/licenses/by/4.0/).

\section{Introduction}

Studying the biological role of metals in ecosystems and their biochemical cycles in the biosphere suggest their dualistic effect: so, a large number of metals are needed for normal processes in living organisms; however, increasing their levels in the ecosystem, metals can have a negative impact on the vital activities of organisms, i.e., demonstrate high toxicity [1$3]$.

Natural sources of heavy metals such as volcanic blowouts, continental dust transfer, and weathering of meta-enriched rocks due to prolonged air exposure significantly increase the number of heavy metals in soils [4-5]. In addition, heavy metals can also contaminate the soil 
as a result of other human activities such as (1) the operation of mines and ironworks; (2) the use of metal-based pesticides and metal-enriched wastewater sediment in agriculture; (3) burning fossil fuels, metallurgical industries and electronics, and (4) military training and armament, etc. The anthropogenic activity can be divided into five groups: (1) metallurgical production and smelting (e.g., As, Cd, $\mathrm{Pb}$, and $\mathrm{Hg}$ ); (2) industry (e.g., As, $\mathrm{Cd}, \mathrm{Cr}, \mathrm{Co}, \mathrm{Cu}, \mathrm{Hg}$, $\mathrm{Ni}$, and $\mathrm{Zn}$ ); (3) atmospheric deposition (As, $\mathrm{Cd}, \mathrm{Cr}, \mathrm{Cu}, \mathrm{Pb}, \mathrm{Hg}$, and $\mathrm{U}$ ); (4) agriculture (e.g., $\mathrm{As}, \mathrm{Cd}, \mathrm{Cu}, \mathrm{Pb}, \mathrm{Se}, \mathrm{U}$, and $\mathrm{Zn}$ ); and (5) waste disposal (e.g., As, $\mathrm{Cd}, \mathrm{Cr}, \mathrm{Cu}, \mathrm{Pb}, \mathrm{Hg}$, and $\mathrm{Zn}$ ) [6-9].

Many works have been devoted to aspects of intoxication of living organisms with heavy metal ions in excessive concentrations [10-12]. Experimental studies show that the introduction of various heavy metals in the form of their soluble salts to laboratory animals can lead to toxic damage to the body [13-15]. Heavy metal salts and oxides toxically affect fibroblasts and other body cells in tissue culture. Many hypotheses on the mechanisms of toxic effects of metals on the body have been proposed, but the main thing is that the toxic effect is carried out through metal ions that interact with different proteins in cells. There have been determined maximum allowable concentrations of heavy metals that are considered safe for people's stay and functioning for soil, water, and air [16-18].

Heavy metals such as $\mathrm{Cd}, \mathrm{Co}, \mathrm{Ni}, \mathrm{Ga}, \mathrm{Pb}, \mathrm{Ti}$, etc., as shown in a number of studies, can cause neoplasms of different localizations [19-21].

Taking into account the concern of the world community with acute and chronic intoxication with heavy metals, methods of detoxification of excessive heavy metal concentrations, as well as their active removal from the body, are actively being developed today. To this end, various detoxers are used [22-25].

A relatively new and safe method of detoxification is the use of probiotic strains that have the ability to bind heavy metals, for example, encrusting them in their cell wall, and further, withdrawing through the gastrointestinal tract. Scientists studied the protective effects of probiotic supplements against toxicity caused by cadmium in rats. Probiotics, in combination with cadmium, have been shown to increase the concentration of this metal in feces. As a result, Cd levels in the blood, the liver, and kidneys, as well as ALT and AST activity in the blood, were reduced compared to the group of rats receiving only cadmium. Besides, probiotics consumed at the same time as cadmium weaken histomorphological changes in the liver and kidneys caused by cadmium. Probiotics are thought to actively promote cadmium excretion through feces, probably due to binding to the cell wall of bacteria [26-30].

\section{Materials and Methods}

The aim of our study was a comprehensive assessment of the effectiveness of probiotic preparations (Table 1).

The experiment utilized three probiotic preparations: "Vetom 2" based on B. subtilis 7048 and B. licheniformis 7038, "Sporobakterin liquid" on B. subtilis 534, and "Baktisubil" based on B. cereus IP 5832.

The preparation "Vetom 2" is a fine powder of white color, sweet taste, odorless, easily soluble in water. One gram of the preparation contains at least $1 \times 10^{6} \mathrm{CFU}$ of living microbial cells. It is comprised of two microorganisms B. subtilis 7048 and B. licheniformis 7038.

The preparation "Sporobakterin liquid" is a suspension of the biomass of living $B$. subtilis 534 of white or slightly yellow color with a specific smell and salty taste, while settling the loose precipitation of different shades from white to light brown forms. 
The preparation "Baktisubtil" is solid gelatin capsules of milky white color, containing amorphous powder of white-grayish or white-yellowish color - spores of B. cereus IP 5832. It has a specific smell; when dissolved, it forms a homogeneous suspension of whitish-grayish color. $\mathrm{CdSO}_{4} \times 8 \mathrm{H}_{2} \mathrm{O}$ was used as a xenobiotic factor.

Table 1. The scheme of the experiment.

Preclinical, experimental trials

\begin{tabular}{l|l|l|l|l|l}
\hline & Dose, $\mathrm{mg} / \mathrm{kg}$ & Control & B. subtilis 534 & B. cereus IP 5832 & $\begin{array}{l}\text { B. licheniformis 7038 } \\
\text { B. subtilis 7048 }\end{array}$ \\
\hline Intact group & - & $\mathrm{K}_{0}(\mathrm{n}=24)$ & - & - & - \\
\hline Control ** & - & & $\mathrm{K}_{3}(\mathrm{n}=24)^{* *}$ & $\mathrm{~K}_{4}(\mathrm{n}=24)^{* *}$ & $\mathrm{~K}_{5}(\mathrm{n}=24)^{* *}$ \\
\hline $\mathrm{CdSO}_{4}^{*}$ & 3 & $\mathrm{~K}_{2}(\mathrm{n}=24)^{*}$ & $\begin{array}{l}\mathrm{O}_{4}(\mathrm{n} \\
24) *(* *)\end{array}$ & $\mathrm{O}_{5}(\mathrm{n}=24) *(* *)$ & $\begin{array}{l}\mathrm{O}_{6} \\
(\mathrm{n}=24) *(* *)\end{array}$ \\
\hline
\end{tabular}

Evaluation of the effectiveness of probiotic strains to correct the elemental status of animals in the creation of experimental intoxication

Determination of CFU of studied The studied material was kept in a water bath for 1 hour at a microorganisms in the blood and feces of temperature of $100 \mathrm{C}$. Biological samples were diluted in distilled the studied animals $* * *$ water at the rate of $1 \mathrm{~g}$ per $10 \mathrm{ml}$ with the subsequent series of dilution of $1: 100 \ldots 1: 10000.50 \mu \mathrm{L}$ from each test tube was injected on beef-extract agar (BEA) and seeded with a lawn with the subsequent calculation of CFU after 24 hours of cultivation.

Study of hematological and biochemical parameters of the blood and parameters of non-specific serum immunity $* * *$

Biochemical (glucose, cholesterol, urea, total protein, ALT, AST, bilirubin, creatinine, alkaline phosphatase) serum parameters were determined using standard methods.

Histological study of target organs***

We chose the liver as the target organ, due to the fact that it is most exposed to heavy metals.

Determining the content of the studied The effectiveness of the probiotic strains was assessed using metals in tissues of experimental atomic-adsorption spectrophotometry. As a biological material of animals*** the study, we used the cutaneous covering and the muscular and bone tissues in the amount of 5 grams of each of the samples.

* $-\mathrm{CdSO}_{4}$ was injected forcibly (individually) once on an empty stomach in the form of water solutions

** - suspensions of microorganisms were administered forcibly (individually) twice a day for 7 days on an empty stomach in the form of a suspension of $0.5 \mathrm{ml}$ in concentration $\left(1 \times 10^{9} \mathrm{CFU} / \mathrm{ml}\right)$

*** - the samples were selected at intervals of 7 days (the background study, 7th, 14th, and 21st days of the experiment). The housing of animals and procedures during the research was carried out in accordance with the requirements of the instructions and recommendations of the Russian Regulations (Order of the Ministry of Health of the USSR No. 755 of 12.08.1977) and "The Guide for the Care and Use of Laboratory Animals (National Academy Press Washington, D.C. 1996)"

\section{Results and Discussion}

One of the factors in assessing the effectiveness of probiotic preparations in intoxication with cadmium was the determination of CFU of the studied microorganisms in the blood (Figure 1) and feces (Figure 2) of experimental animals.

In the course of our research, we found that an increase in CFU with a peak of values by the 21 st day of the experiment was recorded in all the experimental groups and the probiotic control groups throughout the entire experiment.

The findings evidence that the use of probiotic preparations based on bacteria of the genus Bacillus contributes to an increase in the number of these microorganisms at the first stage (the 7th day of the experiment) both in the intestines and in the bloodstream, but, by the 21 st day of the study, the concentration of the studied microorganisms in both the experimental and the probiotic control groups increases rapidly in the circulatory system.

Biochemical examination of serum of the experimental animals allows assessing both the degree of influence of xenobiotics on metabolic processes and the presence of pathological changes in internal organs, in particular the presence of possible degenerative changes in the organs responsible for detoxification (the liver). Based on the above, it follows that the most indicative of the parameters are total bilirubin, ALT, and alkaline phosphatase. 


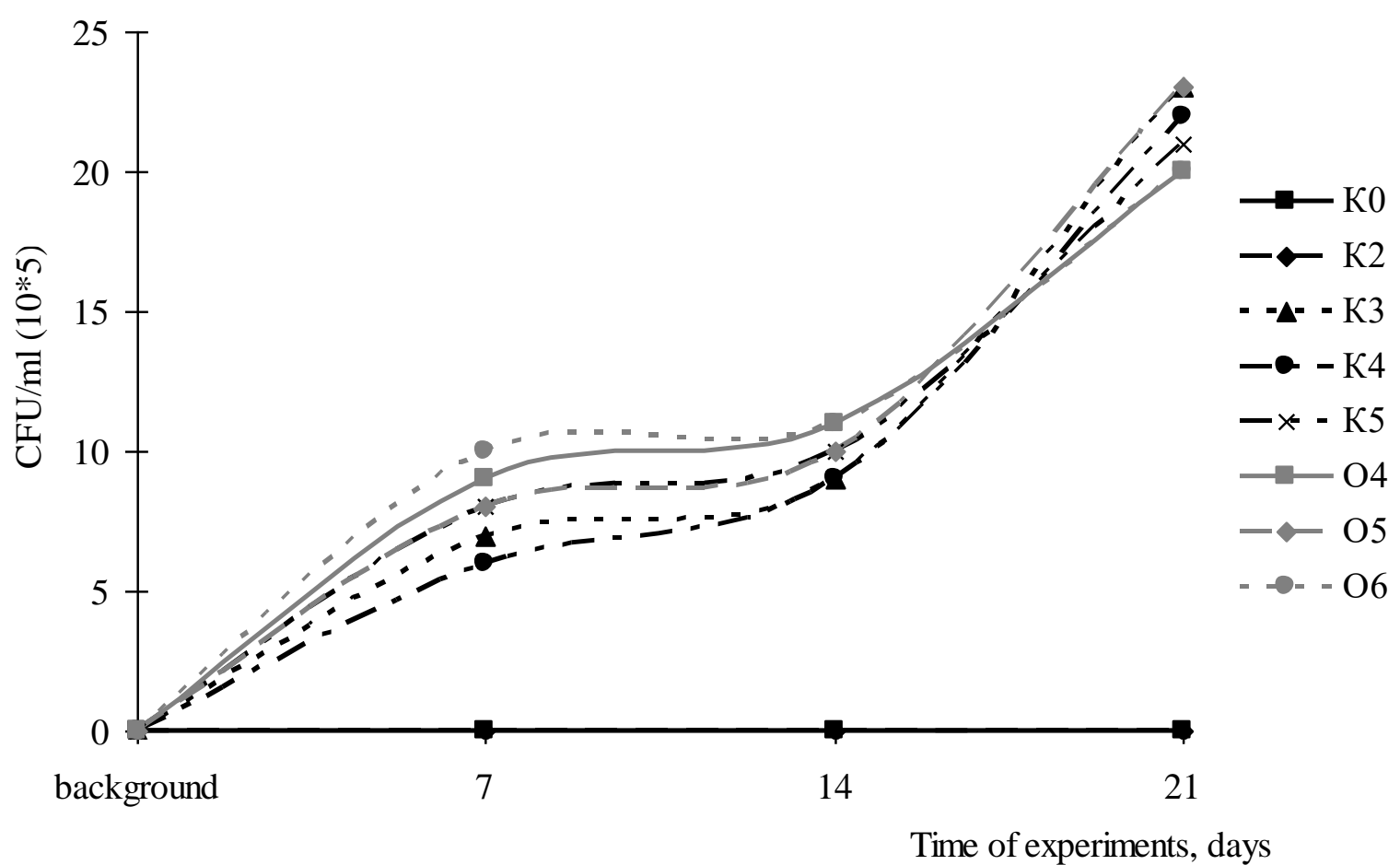

Figure 1. Dynamics of CFU of the studied microorganisms in the blood of laboratory animals in intoxication with cadmium.

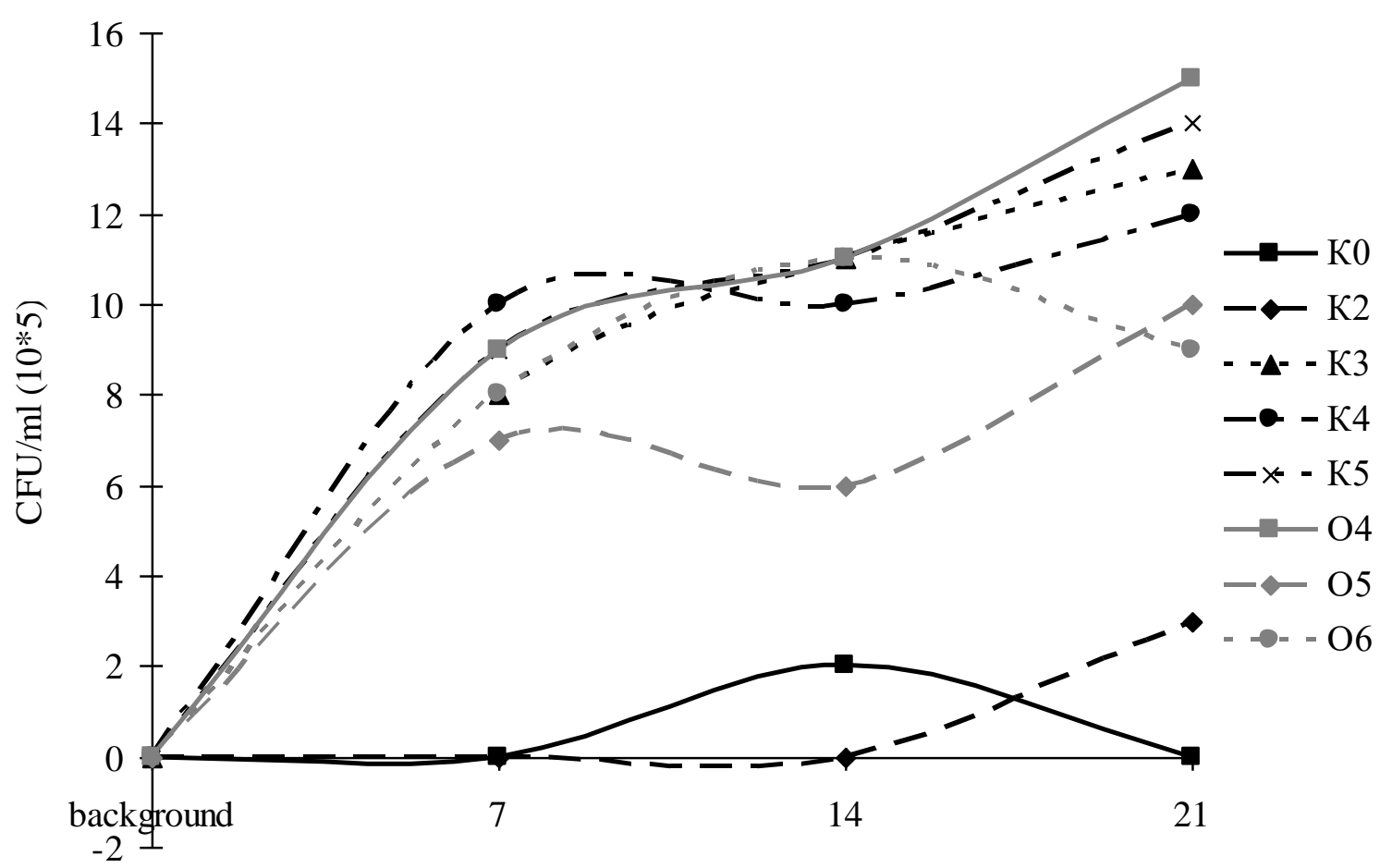

Time of experiments, days

Figure 2. Dynamics of CFU of the studied microorganisms in feces of laboratory animals in intoxication with cadmium.

Bilirubin is one of the intermediate products of hemoglobin decay occurring in the macrophages of the spleen, the liver, and the bone marrow. It is formed by the enzymic 
reduction of biliverdin. Based on these data, it can be assumed that an increase in the concentration of this blood parameter may indicate toxic-related liver damage. In the case of cadmium intoxication, the dynamics pattern looks ambiguous. The content of bilirubin in the experimental groups had higher values both in relation to the general control group and to the cadmium intoxication control group throughout the experiment. We revealed the maintenance of the upward trend in the group where Sporobakterin was used. While in the group where Vetom 2 was used as a drug, bilirubin levels were lower than those in group K0 at the final phase of the study.

Alanine transaminase (ALT) is a special endogenous enzyme. It is included in the group of transferases and the subgroup of aminotransferases. The synthesis of this enzyme takes place intracellularly. A limited amount of ALT enters the blood. Therefore, when a biochemical analysis shows an increased content of ALT, it indicates the presence of a number of abnormalities in the body and the development of serious diseases. They are often associated with degenerative changes in organs, which leads to a sharp release of the enzyme into the blood. It results in the fact that the activity of alanine transaminase also increases. It is difficult to determine the vastness of necrosis or the degree of tissue damage on the basis of this, as the enzyme is uncharacteristic of organ specificity.

Alanine transaminase is found in many organs: kidneys, the heart muscle, the liver, and even skeletal muscles. The main function of the enzyme is amino acid metabolism. It acts as a catalyst for reversible alanine transfers from the amino acid to alpha-ketoglutarate.

The analysis of the dynamics of ALT, as in the case of total bilirubin, has a general pattern to increase this indicator on the 7th day of the experiment, but it should be noted that its concentration in the experimental groups was lower than the control value $\left(\mathrm{K}_{1}\right)$ followed by normalization to the level of the physiological norm by the 21 st day of the experiment.

Alkaline phosphatase is involved in the metabolism of phosphoric acid, splitting it from organic compounds and contributing to the transport of phosphorus in the body. In humans and animals, alkaline phosphatase is present in all tissues, especially in high concentrations in the liver, the bile duct, kidneys, bones, and placenta. Its increase may indicate pathological changes in the liver tissue. The findings confirm our assumptions about the development of the toxic effect of cadmium intoxication, and the exasperation phase gets recorded on the 7 th day of the experiment. However, the value of this indicator in the experimental groups, as well as a number of other analyzed indicators, is reduced to the level of reference values at the final stage of the experiment.

In the liver of the intact group of animals, a poorly expressed lobulation of the organ structure was revealed due to the small amount of the around-lobule connective tissue, although the zones of centrilobular and peripheral hepatocytes are distinct. The organ reveals a classic beam-type structure (Figure 3). Both centrilobular and peripheral cells have different core sizes and, therefore, various levels of their ploidy. Smaller nuclei predominate among peripheral hepatocytes; binuclear hepatocytes dominate among centrilobular cells, which makes up to 1.2 $\pm 0.04 \%$ in absolute amount compared to the peripheral zones with $0.7 \pm 0.05 \%$.

When administering cadmium on the 7th day of the experiment, there were noticed phenomena of moderate hydropic dystrophy mainly among centrilobular hepatocytes (Figure 3 ), which persists by the 21st day of the experiment (Figure 3). This confirms the fact that centrilobular hepatocytes are primarily involved in the biotransformation of xenobiotics. The number of binuclear cells increases to $3.2 \pm 0.1 \%$ among the cells in this zone. The appearance of polyploid binuclear cells is a general regularity of the functioning of the population of 
hepatocytes providing the maintenance of homeostasis at the level of individual zones of the lobule, hence, the entire organ.

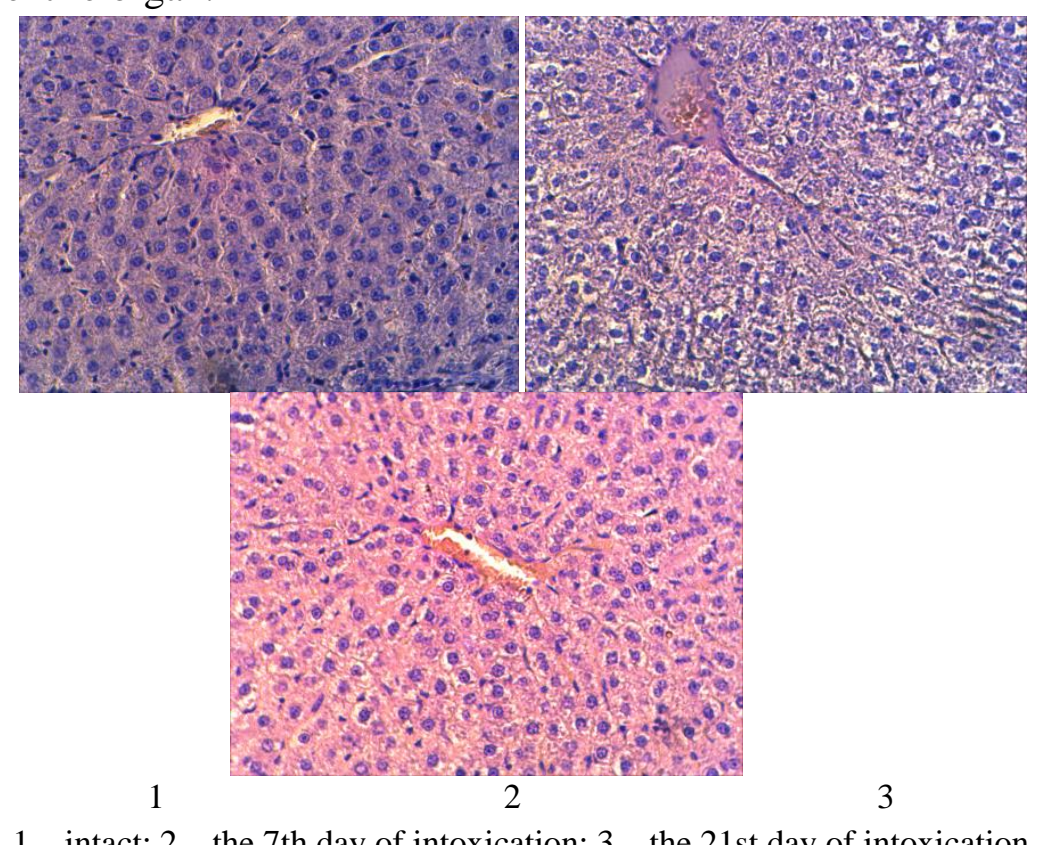

Figure 3 (1-2-3). Fragment of the liver of experimental rats intoxicated with cadmium (x 300)
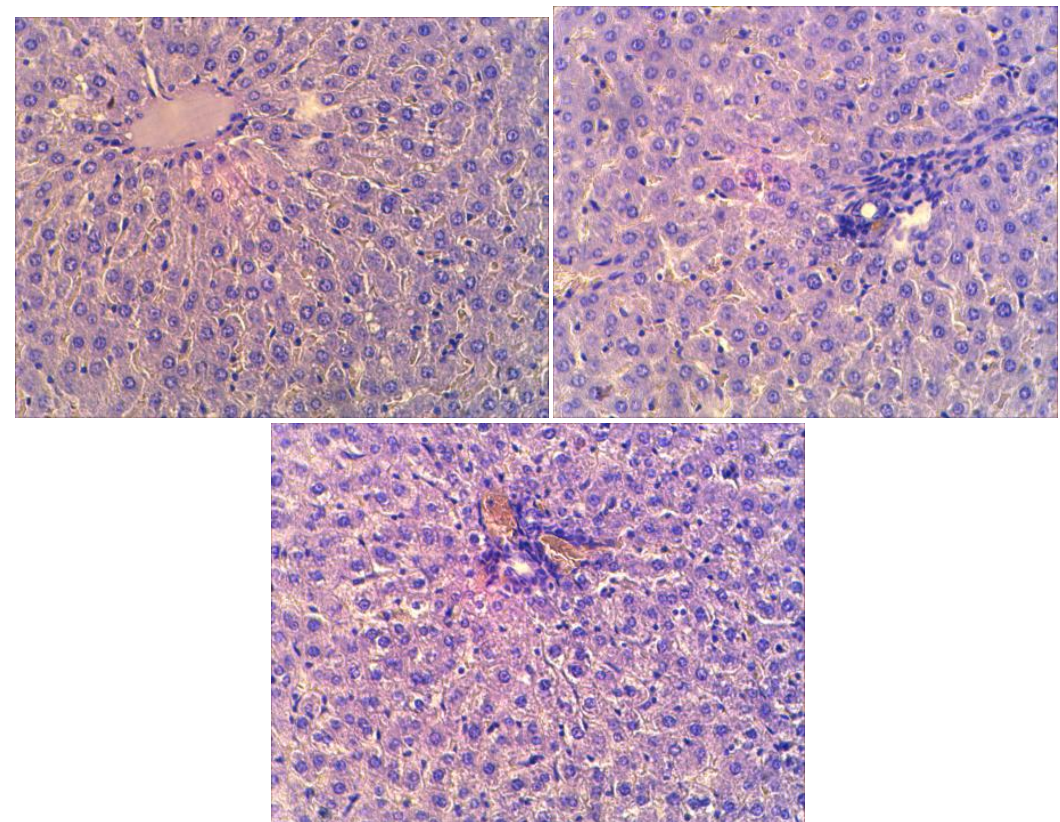

1

2

1 - control of "Baktisubtil"; 2 - 7th day of the experiment; 3 - 14th day of the experiment.

Figure 4 (1-2-3). Fragment of the liver of experimental rats intoxicated with cadmium with the use of "Baktisubtil" as a detox (x 300).

In the study on the effects of "Baktisubtil" on the body of laboratory animals, we found that centrilobular and peripheral hepatocytes that form hepatic beams did not bear structural changes on the 1st day (Figure 4). By the14th day, moderate phenomena of hydropic dystrophy got detected among peripheral hepatocytes (Figure 4). When using "Baktisubtil" against the background of the introduction of cadmium, mild signs of hydropic dystrophy were still present among centrilobular and peripheral hepatocytes. 
When injecting "Sporobakterin" against the background of intoxication with cadmium, the liver showed no dystrophic changes (Figure 5), there were found many, in our opinion, pitcells (Figure 5).

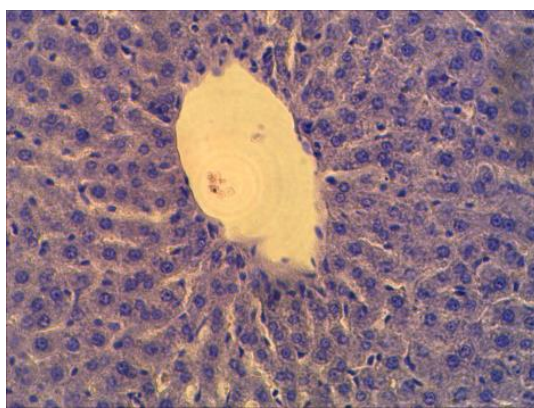

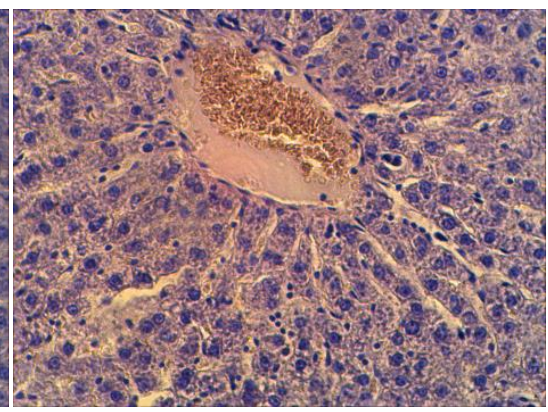

2

$1-14$ th day of the experiment; $2-21$ st day of the experiment.

Figure 5. Fragment of the liver of experimental rats intoxicated with cadmium with the use of "Sporobakterin" as a detox (x 300).

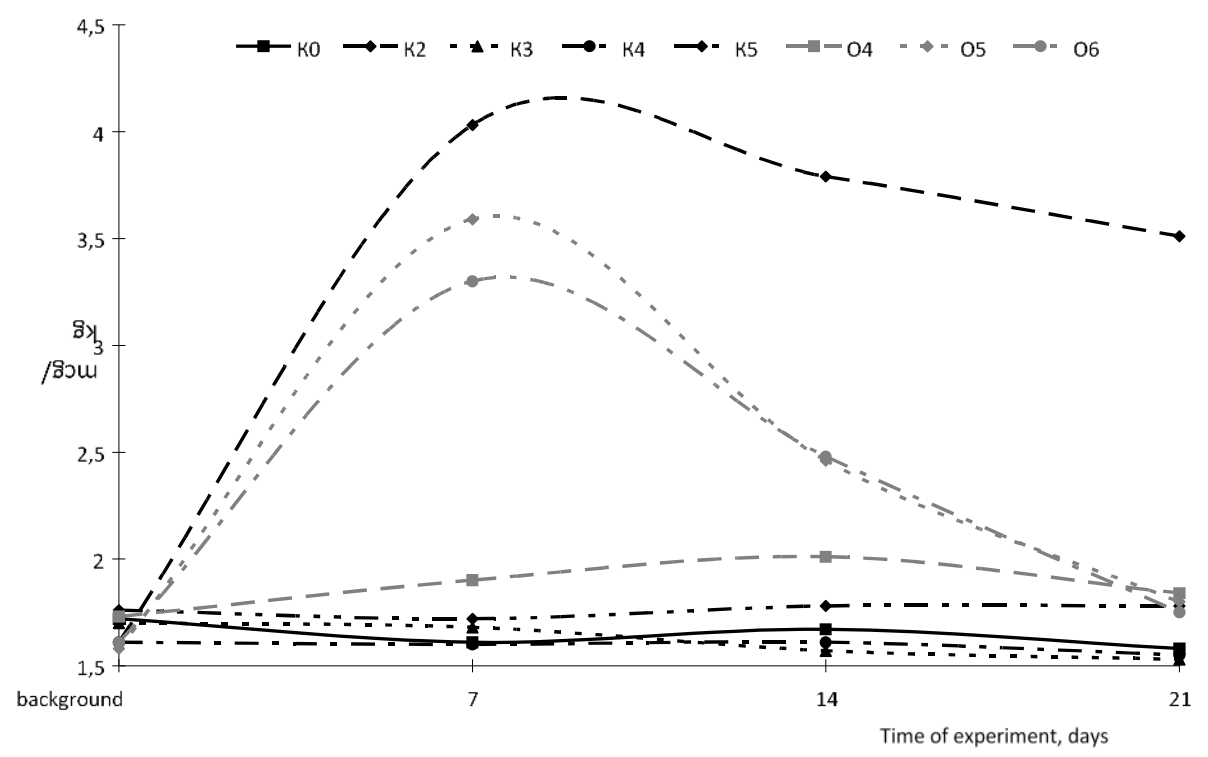

Figure 6. Dynamics of the total concentration of cadmium ions in the tissues (cutaneous covering with hair, the bone, and muscular tissues) of experimental animals.

Thus, the use of different probiotics as a protective substance against the background of intoxication with cadmium showed that the best effect and preservation of the structure of the main cell population of the liver was observed with Vetom 2 during all the periods of observation. There were no microcirculation violations in the liver lobule zones.

The use of only "Baktisubtil" causes dystrophic changes in the liver on the 14th day. When it was used against the background of the introduction of cadmium in hepatocytes, the phenomenon of hydropic dystrophy was maintained.

"Sporobakterin", when used against the background of the introduction of cadmium significantly, normalizes the structure of hepatocytes. When "Sporobakterin" gets injected against the background of intoxication with cadmium, cells of bone-marrow origin get activated (Kupffer cells and pit-cells). The latter, according to literature, being a subpopulation of lymphocytes that have a natural killer activity to damaged hepatocytes, can stimulate the proliferation of liver cells like APUD cells. 
The final stage of the study was the study on the content of cadmium ions in biological samples of the studied animals (Figure 6).

The findings show a significant increase in the concentration of the studied element in the tissues of laboratory animals by the 7th day of the experiment. It should be noted, however, that the experimental group where "Sporobakterin" was used as a biocorrector of the cadmium content, had lower values of the content of the element compared to other experimental groups. In our opinion, this phenomenon can be explained by the fact that, unlike the other preparations, B. subtilis 534 is contained in the preparation in the form of vegetative cells in the liquid form and, as a result, shows its activity immediately after administration.

\section{Conclusions}

Generalizing and interpreting the findings, it should be noted that the use of various probiotic preparations based on bacteria of the genus Bacillus as a protective substance in intoxication with cadmium contributes to the preservation of the structure of the main cell population of the liver - hepatocytes - during all periods of observation. There are no microcirculation violations in the liver lobule zones. On the basis of histological studies, it was stated that probiotics based on bacteria of the genus Bacillus prevented pathological changes in target organs, which may be associated with the effective absorption of heavy metals by probiotic components. Biochemical blood indicators, determination of colony-forming units of the studied microorganisms, and the level of ions of the studied xenobiotic throughout the experiment have an overall correlation. Thus, as the concentration of the studied microorganisms increases, the blood and feces of the studied animals reveal a decrease in the concentration of cadmium cations in biological tissues, which, in turn, led to a decrease in the level of biochemical indicators of blood (ALT, AST, bilirubin, and alkaline phosphatase) to the upper limits of reference values.

As a result of determining the ability of bacteria of the genus Bacillus comprising the studied probiotics to biosorption and elimination of cadmium by means of determining their concentration in the tissues of laboratory animals, it was found that the preparations contribute not only to reducing the toxic effects of cadmium ions on the body but also to reducing the concentration of cadmium ions in comparison with the intoxication control group by more than $50 \%$. At the same time, the most effective preparations are "Sporobakterin" and "Vetom 2".

\section{Funding}

This research received no external funding.

\section{Acknowledgments}

This research has no acknowledgment.

\section{Conflicts of Interest}

The funders had no role in the design of the study; in the collection, analyses, or interpretation of data; in the writing of the manuscript, or in the decision to publish the results. 


\section{References}

1. Sizentsov, A.N.; Kvan, O.V.; Vishnyakov, A.I.; Babushkina, A.E.; Drozdova, E.A. The use probiotic preparations on basis of bacteria of a genu Bacillus during intoxication of lead and zinc. Life science journal 2014, 11, 18-20.

2. Miroshnikov, S.; Kharlamov, A.; Zavyalov, O.; Frolov, A.; Bolodurina, I.; Arapova, O.; Duskaev, G. Method of sampling beef cattle hair for assessment of elemental profile. Pakistan Journal of Nutrition 2015, 14, 632-636, http://dx.doi.org/10.3923/pjn.2015.632.636.

3. Sizentsov, A.N.; Kvan, O.V.; Miroshnikova, E.P.; Gavrish, I.A.; Bykov, A.V.; Serdaeva, V.A. Assessment of biotoxicity of cu nanoparticles with respect to probiotic strains of microorganisms and representatives of the normal flora of the intestine of broiler chickens. Environmental Science and Pollution Research 2018, 25, 15765-15773, https://doi.org/10.1007/s11356-018-1761-4.

4. Kalashnikov, V.; Zajcev, A.; Atroshchenko, M.; Miroshnikov, S.; Frolov, A.; Zavyalov, O.; Kalinkova, L.; Kalashnikova, T. The content of essential and toxic elements in the hair of the mane of the trotter horses depending on their speed. Environmental Science and Pollution Research 2018, 25, 21961-21967, https://doi.org/10.1007/s11356-018-2334-2.

5. Hamid E.; Hamid, M. Synthesis and characterization of copper ferrite nanoparticles and its application as MRI contrast agent. Letters in Applied NanoBioscience 2019, 8(1), 541-544, https://doi.org/10.33263/LIANBS81.541544.

6. Sizentsov, A.; Karpova, G.; Klimova, T.; Salnikova, E.; Kvan, O.; Barysheva, E.; Gavrish, I. Evaluation of anionic components of lead on biotoxicity and bioaccumulation ability in respect of probiotic stamps. International Journal of GEOMATE 2019, 16 , 8-13, https://doi.org/10.21660/2019.55.76923.

7. Wisch, J.K.; Farrell, E.; Siegel, M.; Freyermuth, S. Misconceptions and persistence: resources for targeting student alternative conceptions in biotechnology. Biochem Mol Biol Educ. 2018, https://doi.org/10.1002/bmb.21176.

8. Moro, L.; Pezzotti, G.; Turemis, M.; Sanchís, J.; Farré, M.; Denaro, R.; Giacobbe, M.G.; Crisafi, F.; Giardi, M.T. Fast pesticide pre-screening in marine environment using a green microalgae-based optical bioassay. Mar Pollut Bull. 2018, 129, 212-221, https://doi.org/10.1016/j.marpolbul.2018.02.036.

9. Boriani, F.; Fazio, N.; Bolognesi, F.; Pedrini, F.A.; Marchetti, C.; Baldini, N. Noncellular modification of Acellular Nerve Allografts for peripheral nerve reconstruction: A systematic critical review of the animal literature. World Neurosurg 2018, 18, 32502-32506, https://doi.org/10.1016/j.wneu.2018.10.195.

10. Kvan, O.; Duskaev, G.; Rakhmatullin, S.; Kosyan, D. Changes in the content of chemical elements in the muscle tissue of broilers on the background of plant extract and tetracyclines. International Journal of Environmental Science and Development 2019, 10, 419-423, https://doi.org/10.18178/ijesd.2019.10.12.1209.

11. Subhanandaraj, T.T.; Raghavan, K.T.; Narayanan, R. Antibacterial and antibiofilm activity of probiotic based silver nanoparticles is a green approach in biomedical applications. Letters in Applied NanoBioScience 2020, 9(2), 988-994, https://doi.org/10.33263/LIANBS92.988994.

12. Bhattacharya, S. The Role of Probiotics in the Amelioration of Cadmium Toxicity. Biol Trace Elem Res 2020. doi: $10.1007 / \mathrm{s} 12011-020-02025-x$. Online ahead of print.

13. Lu, L.; Liao X.; Luo X. Nutritional strategies for reducing nitrogen, phosphorus and trace mineral excretions of livestock and poultry. Journal of Integrative Agriculture 2017, 16, 2815-2833, https://doi.org/10.1016/S2095-3119(17)61701-5.

14. Banwo, K.; Alonge, Z.; Sanni, A.I. Binding Capacities and Antioxidant Activities of Lactobacillus Plantarum and Pichia Kudriavzevii Against Cadmium and Lead Toxicities. Biol Trace Elem Res 2020. doi: 10.1007/s12011-020-02164-1. Online ahead of print.

15. Wang, N.; Jiang, M.; Zhang, P.; shu, H.; Li, Yu.; Guo, Zh. Amelioration of Cd-induced Bioaccumulation, Oxidative Stress and Intestinal Microbiota by Bacillus Cereus in Carassius Auratus Gibelio. Chemosphere 2020, 245, 125613. doi: 10.1016/j.chemosphere.2019.125613.

16. Kvan, O.; Gavrishm, I.; Lebedev, S.; Korotkova, A.; Miroshnikova, E.; Bykov, A.; Serdaeva, V.; Davydova, $\mathrm{N}$. Effect of probiotics on the basis of Bacillus subtilis and Bifidobacterium longum on the biochemical parameters of the animal organism. Environmental Science and Pollution Research 2018, 25, 2175-2183, https://doi.org/10.1007/s11356-017-0534-9.

17. Deryabin, D.G.; Efremova, L.V.; Karimov, I.F.; Manukhov, I.V.; Gnuchikh, E.Y.; Miroshnikov, S.A. Comparative Sensitivity of the Luminescent Photobacterium phosphoreum, Escherichia coli, and Bacillus subtilis Strains to Toxic Effects of Carbon-Based Nanomaterials and Metal Nanoparticles. Mikrobiologiia 2016, 85, 177-86, https://doi.org/10.1134/S0026261716020053.

18. Ouwehand, A. C.; Forssten, S.; Hibberd, A. A.; Lyra, A.; Stahl, B. Probiotic approach to prevent antibiotic resistance. Ann Med. 2016, 48, 246-55, https://doi.org/10.3109/07853890.2016.1161232.

19. Jotham, S.; Niv, Z.; Eran, S.; Eran, E. The Pros, Cons, and Many Unknowns of Probiotics. Nat Med. 2019, 25, 716-729, https://doi.org/10.1038/s41591-019-0439-x.

20. Podolian, J. Effect of probiotics on the chemical, mineral, and amino acid composition of broiler chicken meat. Ukrainian Journal of Ecology 2017, 7, 61-65, https://doi.org/10.15421/20178. 
21. Kotoky, Rh.; Pandey, P. Rhizosphere Assisted Biodegradation of Benzo(a)pyrene by Cadmium Resistant Plant-Probiotic Serratia Marcescens S2I7, and Its Genomic Traits. Sci Rep 2020, 10(1), 5279. doi: 10.1038/s41598-020-62285-4.

22. Kim, S.-K.; Guevarra, R.B.; Kim, Y.-T.; Kwon, J.; Kim, H.; Cho, J.H.; Kim, H.B.; Lee, J.-H. Role of probiotics in human gut microbiome-associated diseases. J. Microbiol. Biotechnol 2019, 29, 1335-1340, https://doi.org/10.4014/jmb.1906.06064.

23. Hossein-khannazer, N.; Azizi, G.; Eslami, S. et al. The Effects of Cadmium Exposure in the Induction of Inflammation. Immunopharmacol Immunotoxicol 2020, 42(1), 1-8. doi: 10.1080/08923973.2019.1697284.

24. Lorena, V.V.; Miguel, G.; Patricia, R.M. Probiotics for Prevention and Treatment of Clostridium Difficile Infection. Adv Exp Med Biol. 2018, 1050, 161-176, https://doi.org/10.1007/978-3-319-72799-8_10.

25. Golik, V.I.; Dmitrak, Yu. V.; Gabaraev, O.Z.; Kozhiev, K. Minimization of the the impact of mining on the environment. Ekologiya i promyshlennost Rossii 2018, 22, 26-29. (Russia)

26. Kim, C.H.; Choi, Y.H.; Jeong, M.Y.; Chang, J.S.; Yoon, P.W. Cobalt intoxication heart failure after revision total hip replacement for ceramic head fracture: a case report. Hip \& pelvis 2016, 28, 259-263, https://doi.org/10.5371/hp.2016.28.4.259.

27. Underwood, M. Probiotics and the Prevention of Necrotizing Enterocolitis. J Pediatr Surg. 2019, 54, 405412, https://doi.org/10.1016/j.jpedsurg.2018.08.055.

28. Guandalini, S.; Sansotta, N. Probiotics in the Treatment of Inflammatory Bowel Disease. Adv Exp Med Biol. 2019, 1125, 101-107, https://doi.org/10.1007/5584_2018_319.

29. Wang, J.; Ji, H. Influence of Probiotics on Dietary Protein Digestion and Utilization in the Gastrointestinal Tract. Curr Protein Pept Sci. 2019, 20, 125-131, https://doi.org/10.2174/1389203719666180517100339.

30. Santacroce, L.; Charitos, I.A.; Bottalico, L. A Successful History: Probiotics and Their Potential as Antimicrobials. Expert Rev Anti Infect Ther. 2019, 17, 635-645, https://doi.org/10.1080/14787210.2019.1645597.

31. Mohamed, S.A.; Adham, A.; Khaled, M.; Bakry, A. Organic Selenium, Probiotics, and Prebiotics Effects on Growth, Blood Biochemistry, and Carcass Traits of Growing Rabbits During Summer and Winter Seasons. Biol Trace Elem Res. 2018, 186, 162-173, https://doi.org/10.1007/s12011-018-1293-2. 